\section{Foreign Body in the Oesophagus}

\section{Brit. med. F., 1965, 2, 1042}

Children and infants are apt to swallow a multitude of articles, such as beads, buttons, hair, coins, toys, fruit stones, and so on. For the most part the swallowed objects, depending of course on their size and shape, pass through the alimentary tract and are excreted without causing undue harm to the patient; however, on occasion, even a smooth swallowed object can be the cause of dire effects, as in the patient whose history is reported here.

\section{CASE RePort}

Early in the morning of Boxing Day 1964 a boy aged 2 years 3 months was admitted to the British Military Hospital, Munster, having just vomited approximately 1 pint $(0.6$ litres) of bright red blood. The only history given by the parents was that he had been off his food and miserable for one week. On examination the child had pale mucosae, a pulse rate of 120 per minute, and was apyrexial. Nothing abnormal was detected in the chest or abdomen.

The results of laboratory tests were as follows: haemoglobin, 10 g. $/ 100 \mathrm{ml}$; ; packed cell volume, $30 \%$; white blood cell count, 17,000/c.mm. ; platelets, $112,000 /$ c.mm.

While a possible diagnosis was being considered the parents said that they thought he had swallowed a 10-pfennig coin a week earlier. Radiography of the chest revealed a coin lodged at the level of the tracheal bifurcation. There was no evidence of air in the mediastinum (see Fig.). Blood transfusion was started, and oesophagoscopy was performed. The coin was found at approximately $20 \mathrm{~cm}$. distance from the upper teeth, and was removed without difficulty and without causing bleeding. The coin measured $22 \mathrm{~mm}$. in diameter and was discoloured to a dark green. (The German Federal Government coins of this value consist of a central iron core coated with an alloy of copper and zinc.)

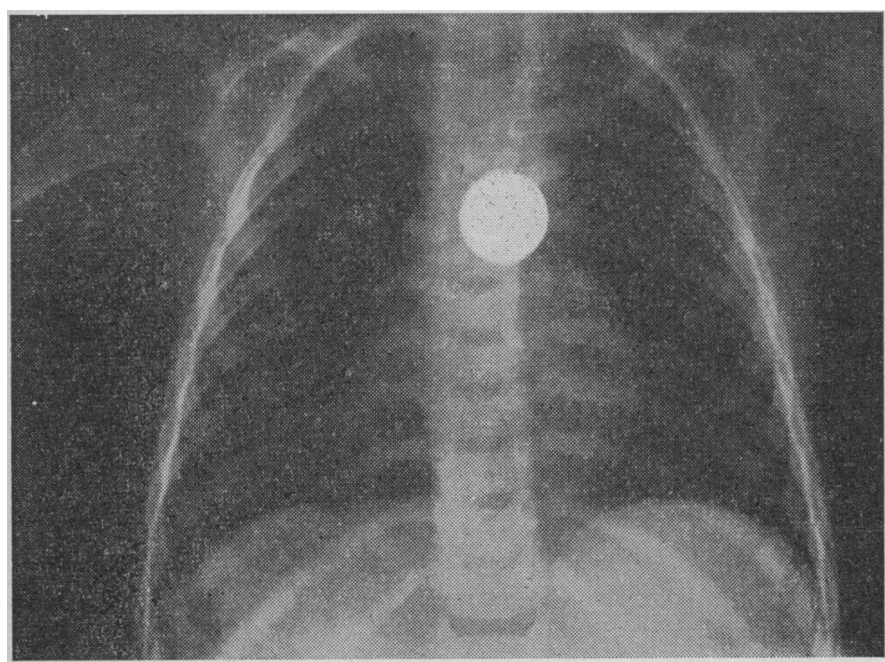

Roentgenogram of chest showing coin lodged in oesophagus just above tracheal bifurcation.

About two hours after the removal of the coin the child had another massive haematemesis, and, despite all attempts at resuscitation, died shortly afterwards.

At necropsy two longitudinally placed ulcers were seen on opposite sides of the oesophageal wall, above the tracheal bifurcation. The ulcer on the right side had nearly, but not quite, perforated the oesophagus, and blood had tracked down from the ulcer to the hilus of the right lung. The ulcer on the left side had gone right through the oesophageal wall, so that a probe could be passed without much difficulty through the oesophagus into distal portion of the aortic arch, and vice versa. The stomach was fully distended with blood, and blood could be sien at various levels all the way down the intestinal tract.

\section{COMMENT}

Most swallowed foreign bodies are held up in the cervical portion of the oesophagus, at its beginning; the next most common site for the impaction of objects is at its diaphragmatic end. Though small sharp objects like pins, spicules of bones, and so on, may be found at any level of the oesophagus, the lodgment of smooth objects at the aortic indentation is not common (Holinger, 1964).

Whatever its nature, a foreign body stuck in the oesophagus must be removed under direct vision as soon as the diagnosis is confirmed. Apart from prolonging the patient's discomfort, delay will make subsequent attempts at removal only more difficult, and the risk of perforation becomes more possible and indeed probable as time goes on. Smooth objects, however, will obviously require more time to ulcerate through the oesophageal wall than sharp and rough ones, and in some cases may stay lodged for months-" some have been present for years" (Neilson, 1948). Thus, Grey Turner (1910), discussing the deaths of five patients caused by perforation of the aorta by foreign bodies, reported that while a boy who had swallowed a smooth object (a halfpenny) survived for 22 months, three of the other four patients who had swallowed sharp objects (rabbit bones, fish bones) all died within seven days. Our patient was unfortunate in that a smooth object did lodge in the oesophageal indentation corresponding to the aortic arch, and there it rapidly perforated the wall through the aorta in the unusually short period of seven days.

Oesophago-aortic fistulas are fortunately not common. Henry and Miscall (1960) observed that only one case had been seen in two large thoracic surgical centres in New York in 25 years ; while Negus and Bateman (1955) state that "a coin has been known to ulcerate through the oesophageal wall and perforate the aorta, an extremely rare occurrence." In fact, only about 83 instances of these fistulas, commonly caused by sharp foreign bodies, have been recorded in the literature, and all terminated fatally (Flavell, 1963).

The diagnosis of foreign bodies in the oesophagus depends on the following triad: clinical history, roentgenoscopy, and oesophagoscopy. One striking diagnostic feature in relation to oesophago-aortic fistulas is the "signal" haemorrhage which precedes the fatal haemorrhage by a variable interval ranging from a few hours to a few days (Barrie and Townrow, 1946). This classical sign was seen in our patient as stated above.

In view of the fatal outcome so far reported in patients suffering from these dreaded fistulas, open thoracic surgery, the new "gold leaf" technique (B.M.F., 1964), and advances in vascular surgery may prove of value to change an otherwise hopeless prognosis.

We would like to thank the Assistant Director of Pathology, B.A.O.R., and the Officer Commanding, British Military Hospital, Munster, for permission to publish this case.

\section{E. E. VẽLla, R.A.M.C., B.SC., M.D., D.T.M.\&H., D.C.P., M.C.PATH., \\ Pathologist, Central Pathology Laboratory, B.A.O.R.}

P. J. BOOTH, R.A.M.C., M.B., B.S., D.L.O., E.N.T. Specialist, British Military Hospital, Munster, B.A.O.R.

\section{REFERENCES}

Barrie, H. J., and Townrow, V. (1946). F. Laryngol., 61, 38.

Brit. med. 7., 1964, 2, 1612.

Flavell, G. (1963). The Oesophagus, p. 71. Butterworth, London. Flavell, G. (1963). The Oesophagus, p. 71.

Grey Turner, G. (1910). Lancet, 1, 1335. 258.

Holinger, P. H. (1964). In Textbook of Paediatrics, edited by W. E. Nelson, 8th ed., p. 692. Saunders, London.

Negus, V. E., and Bateman, G. H. (1955). In St. Clair Thompson's Diseases of the Nose and T.hroat, 6th ed. p. 843. Cassell, London.

Neilson, D. F. A. (1948). In Romanis and Mitchiner's The Science and Practice of Surgery, 8th ed., Vol. 2, p. 286. Churchill, London. 